\title{
Analysis of 6-Pulse and 12-Pulse in Conversion of the 115VAC/400Hz to 270 VDC for Application on Fighter
}

\author{
D R Agustiningsih"1, ${ }^{*}$, E Suwondo ${ }^{1}$, M Kusni $^{1}$ \\ 1 Aerospace Engineering Department, Faculty of Mechanical and Aerospace Engineering Bandung Institute \\ of Technology \\ * Correspondence: dwirochma15@gmail.com
}

Received: 12 August 2019; Accepted: 28 October 2019; Published: 30 December 2019

\begin{abstract}
The development of aircraft secondary power technology is moving from mechanical power, pneumatic power and hydraulic power to electric power. The trend toward electric power is known as More Electric Aircraft (MEA). Modern military aircraft are designed using 270VDC for electric power system. Today, some military aircraft still use $115 \mathrm{VAC} / 400 \mathrm{~Hz}$ for their electrical power system. If this type of aircraft need provides 270VDC electrical power, then they require Multi-Pulse Transformer Rectifier Unit (TRU). The development of this type TRU has not been aimed to comply with aircraft military standards. This research investigates the variation of the number of pulses (p) and firing angle $(\alpha)$ to the amplitude ripple voltage, output voltage, and distortion factor in order to comply with the MIL-STD-704F standards. The multi-pulse transformer rectifier unit being analyzed consists of 6-Pulse and 12-Pulse. The research shows that the amplitude ripple voltage and distortion factor of the 6-Pulse TRU do not comply MIL-STD-704F. The amplitude ripple voltage and distortion factor of 12-Pulse comply MIL-STD-704F with firing angle $(\alpha) \leq 4^{\circ}$.
\end{abstract}

Keywords: Transformer Rectifier Unit, thyristor, ripple voltage, distortion factor, firing angle

\section{Introduction}

The development of power technology used by aircraft has changed from mechanical, pneumatic and hydraulic sources replaced by electric sources known as More Electric Aircraft (MEA). Modern military aircraft that have implemented MEA are JSF F-35 and F-22 Raptor aircraft. The military aircraft uses a 270 VDC electrical system [1]. Figure 1 shows the development of the aircraft electrical system currently using 270/350/540 VDC.

Conventional military aircraft sources still use 115VAC / $400 \mathrm{~Hz}$ to provide power for every electrical load. If the development of the $115 \mathrm{VAC} / 400 \mathrm{~Hz}$ system on conventional military aircraft gets a load that works with a voltage of 270 VDC, conventional military aircraft require a Multi-Pulse Transformer Rectifier Unit to convert 115VAC to a 270 VDC voltage. 


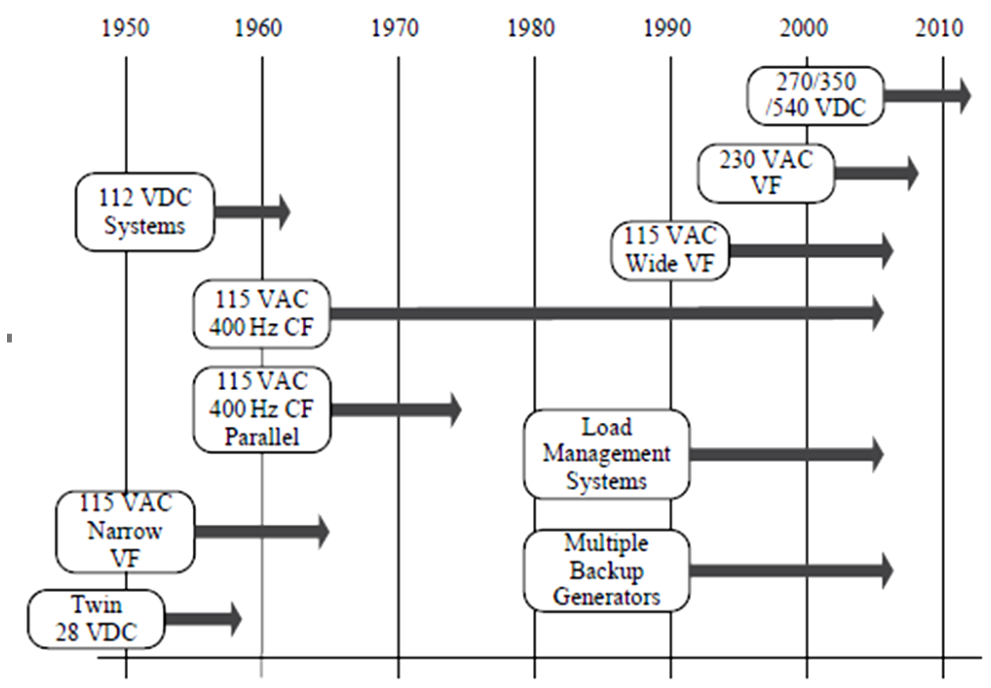

Figure 1. Evolution of Electrical Systems

There are several types of power electrics used by aircraft today. The comparison of types for electrical power generation systems in several military and civil aircraft is shown in Table 1.

Table 1. Development of Military and Civil Aircraft Electric Systems

\begin{tabular}{|c|c|c|c|}
\hline \multirow{2}{*}{$\begin{array}{l}\text { Generation type } \\
\text { IDG/CF } \\
{[115 \mathrm{VAC} / 400 \mathrm{~Hz}]}\end{array}$} & \multicolumn{2}{|c|}{ Civil application } & \multirow{2}{*}{$\begin{array}{l}\text { Military application } \\
\text { Eurofighter Typhoon }\end{array}$} \\
\hline & $\begin{array}{l}\text { B777 } \\
\text { A340 } \\
\text { B737NG } \\
\text { MD-12 } \\
\text { B747-X } \\
\text { B717 } \\
\text { B767-400 }\end{array}$ & $\begin{array}{l}2 \times 120 \mathrm{kVA} \\
4 \times 90 \mathrm{kVA} \\
2 \times 90 \mathrm{kVA} \\
4 \times 120 \mathrm{kVA} \\
4 \times 120 \mathrm{kVA} \\
2 \times 40 \mathrm{kVA} \\
2 \times 120 \mathrm{kVA}\end{array}$ & \\
\hline $\begin{array}{l}\text { VSCF (Cycloconverter) } \\
{[115 \text { VAC / } 400 \mathrm{~Hz}]} \\
\text { VSCF (DC Link) } \\
{[115 \text { VAC / } 400 \mathrm{~Hz}]}\end{array}$ & $\begin{array}{l}\text { B777 } \\
\text { (Backup) } \\
\text { MD-90 }\end{array}$ & $\begin{array}{l}2 \times 20 \mathrm{kVA} \\
2 \times 75 \mathrm{kVA}\end{array}$ & $\begin{array}{ll}\mathrm{F}-18 \mathrm{C} / \mathrm{D} & 2 \times 40 / 45 \mathrm{kVA} \\
\mathrm{F}-18 \mathrm{E} / \mathrm{F} & 2 \times 60 / 65 \mathrm{kVA}\end{array}$ \\
\hline $\begin{array}{l}\text { VF } \\
\text { [115 VAC / 380-760 Hz } \\
\text { typical] }\end{array}$ & $\begin{array}{l}\text { Global Ex } \\
\text { Horizon } \\
\text { kVA } \\
\text { A380 }\end{array}$ & $\begin{array}{l}4 \times 40 \mathrm{kVA} \\
2 \times 20 / 25 \\
4 \times 150 \mathrm{kVA}\end{array}$ & $\begin{array}{l}\text { Boeing JSF } 2 \times 50 \mathrm{kVA} \\
{[\mathrm{X}-32 \mathrm{~A} / \mathrm{B} / \mathrm{C}]}\end{array}$ \\
\hline $\begin{array}{l}\text { VF } \\
230 \text { VAC }\end{array}$ & B787 & $4 \times 250 \mathrm{kVA}$ & \\
\hline 270 VDC & & & $\begin{array}{l}\text { F-22 Raptor } 2 \times 70 \mathrm{kVA} \\
\text { Lockheed-Martin F-35 - } \\
\text { Under Review }\end{array}$ \\
\hline
\end{tabular}

Several researches about the Multi-Pulse Transformer Rectifier Unit have been carried out. Research from [2] introduces several Multi-Pulse Transformer Rectifier Unit topologies namely 6-pulse rectifier, 12-pulse rectifier, 18-pulse rectifier, and 24-pulse rectifier. Also, it is mentioned that military aircraft and civil aircraft use a 6-pulse rectifier and 12-pulse rectifier topology to convert $\mathrm{AC}$ to $\mathrm{DC}$. In the $\mathrm{AC}$ to $\mathrm{DC}$ conversion process, there are two types of rectifiers, namely uncontrolled rectifiers and controlled rectifiers. The uncontrolled rectifier uses a diode for the $\mathrm{AC}$ to $\mathrm{DC}$ conversion process, but other research states that the diode cannot be used for HVDC (High Voltage DC) converters because it cannot properly 
adjust the current flow time selection. Whereas, the controlled rectifier can adjust the output voltage by adjusting the firing angle $(\alpha)$ of the thyristor [3].

The process of converting AC to DC in the Transformer Rectifier Unit (TRU) causes a ripple voltage on the rectifier output voltage. Therefore, the Transformer Rectifier Unit (TRU) as a power source that serves DC loads must meet MIL-STD-704F. Some requirements that must be met are the output voltage in steady state conditions (250-280 VDC), ripple voltage limit (maximum 6 VDC) and distortion factor (maximum 0.015).

MIL-STD-704F standard establishes the requirements and characteristics of aircraft electric power provided at the input terminals of electric utilization equipment, as shown in Table 2. The standard aims to ensure compatibility between the aircraft electric system, external power, and airborne utilization equipment.

Table 2. AC and DC normal operation characteristics (MIL-STD-704F)

\begin{tabular}{|l|l|}
\hline \multicolumn{2}{|c|}{ AC BUS } \\
\hline Steady State Voltage & 108.0 to 118.0 Volts, RMS \\
\hline Frequency (f) & $400 \mathrm{~Hz}$ \\
\hline & 270DC BUS \\
\hline Steady State Voltage & 250.0 to 280.0 Volts \\
\hline Distortion Factor & 0.015 Maximum \\
\hline Ripple Amplitude & 6.0 Volts Maximum \\
\hline
\end{tabular}

\section{Literature Study}

Multi-Pulse Transformer Rectifier circuit consists of a voltage source, transformer, rectifier, RLC circuit. Figure 2 shows a 6-pulse TRU circuit diagrams block while Figure 3 shows a 12-pulse TRU diagram block.

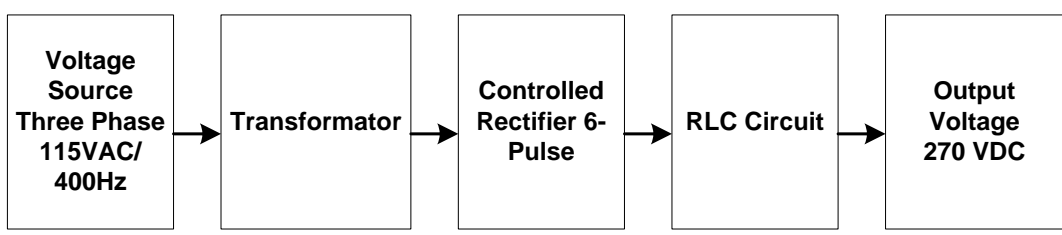

Figure 2. TRU 6- Pulse Block simulation diagram block

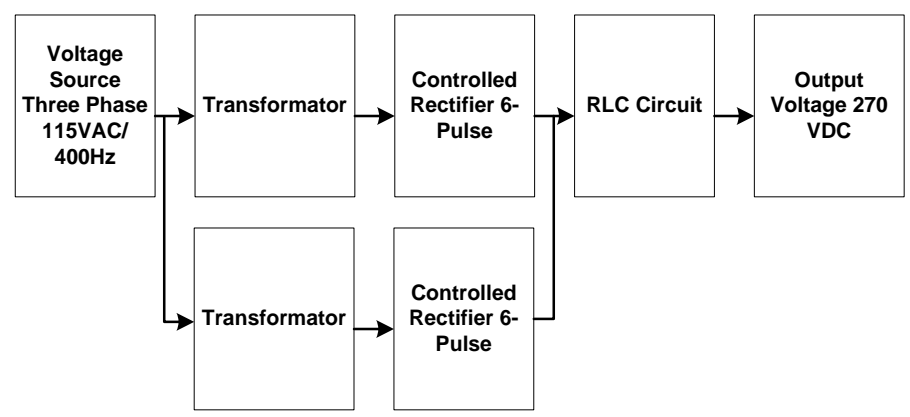

Figure 3. TRU 12- Pulse Block simulation diagram block

The process of converting from AC voltage to DC voltage will produce a ripple voltage at the rectifier output voltage. Therefore, some parameters must meet MIL STD-704F for TRU analysis. The mathematical equations have been carried out by [7], so that the following equations are obtained: 
1. RMS Voltage

$$
\begin{gathered}
\mathrm{V}_{\mathrm{RMS}}=\frac{V m}{\sqrt{2}} \sqrt{1+\frac{F p \cos (2 \alpha)}{2 \pi}} \quad \text { for } \alpha \leq \theta_{\mathrm{L}} \\
\mathrm{V}_{\mathrm{RMS}}=\frac{V m}{\sqrt{2}} \sqrt{\frac{2+p}{4}-\frac{\alpha p}{360}+\frac{E p \sin (2 \alpha)}{4 \pi}+\frac{F p \cos (2 \alpha)}{4 \pi}} \text {, for } \alpha \geq \theta \mathrm{L}
\end{gathered}
$$

2. Average Voltage (Vavg)

$$
\begin{gathered}
\mathrm{V}_{\mathrm{avg}}=\frac{A p V m}{\pi} \cos \alpha, \text { for } \alpha \leq \theta \mathrm{L} \\
\mathrm{V}_{\mathrm{avg}}=\frac{p V m}{2 \pi}\left[1+\cos \left(\alpha+\theta_{\mathrm{L}}\right)\right], \text { for } \alpha \geq \theta \mathrm{L}
\end{gathered}
$$

3. RMS Ripple Voltage VRMS-ripple and Distortion Factor

$$
\begin{gathered}
\mathrm{V}_{\mathrm{RMS}-\text { ripple }}=\sqrt{V_{\mathrm{RMS}}{ }^{2}-\text { Vavg }^{2}} \\
\text { Distortion Factor }=\frac{\text { RMS Ripple Voltage }}{\text { Average Voltage }}
\end{gathered}
$$

4. Critical Inductance

$$
\begin{gathered}
\mathrm{L}=\frac{R \tan \alpha}{\omega}\left(1-\frac{\pi B}{A P}\right), \text { for } \alpha \geq \alpha_{\mathrm{b}} \\
\mathrm{L}=\frac{R}{\omega A \cos \alpha}\left[\left(\frac{\pi}{p}\right) \cos (\theta+\theta \mathrm{L})+\mathrm{A} \sin \alpha+\mathrm{A}\left(\frac{\theta \pi}{180}-\frac{\alpha \pi}{180}-\frac{\pi}{P}\right) \cos \alpha\right], \text { for } \alpha \leq \alpha \mathrm{b} \\
\theta=\sin -1\left(\frac{A p}{\pi} \cos \alpha\right)-\theta_{\mathrm{L}}
\end{gathered}
$$

\section{Simulation of the system characteristics}

The results from equations (1) and (2) for RMS voltage, equation (3) and (4) for average voltage, equation (5) for RMS ripple voltage (VRMS-ripple), equation (6) for distortion factors (VRMS / Vavg) with an input voltage $(\mathrm{Vm})=280 \mathrm{VDC}$, are shown in Figure 4 for 6-pulses and Figure 5 for 12 pulses.

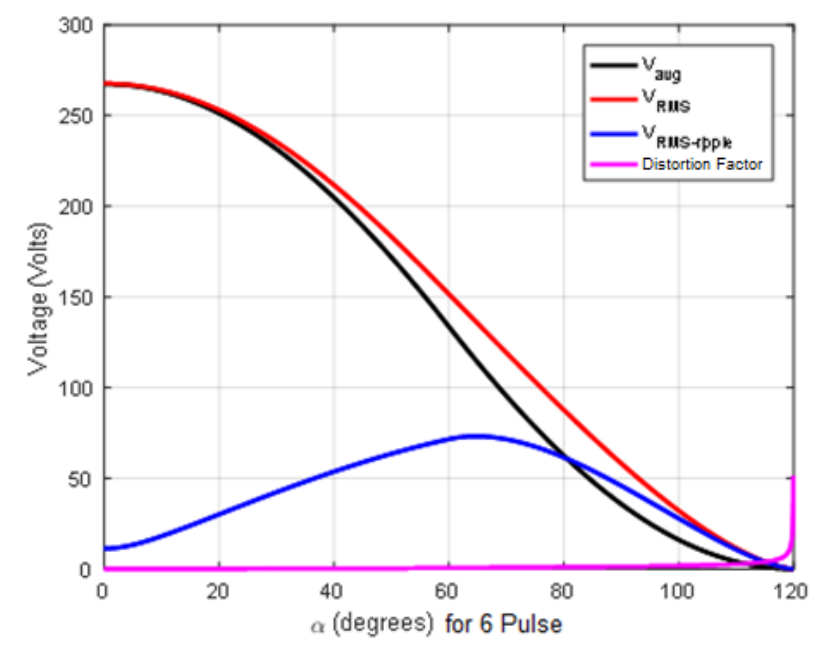

Figure 4. Average Voltage (Vavg), RMS Voltage (VRMS), RMS Ripple Voltage (VRMS_ripple), Distortion Factor (VRMS / Vavg) for 6-pulse TRU 


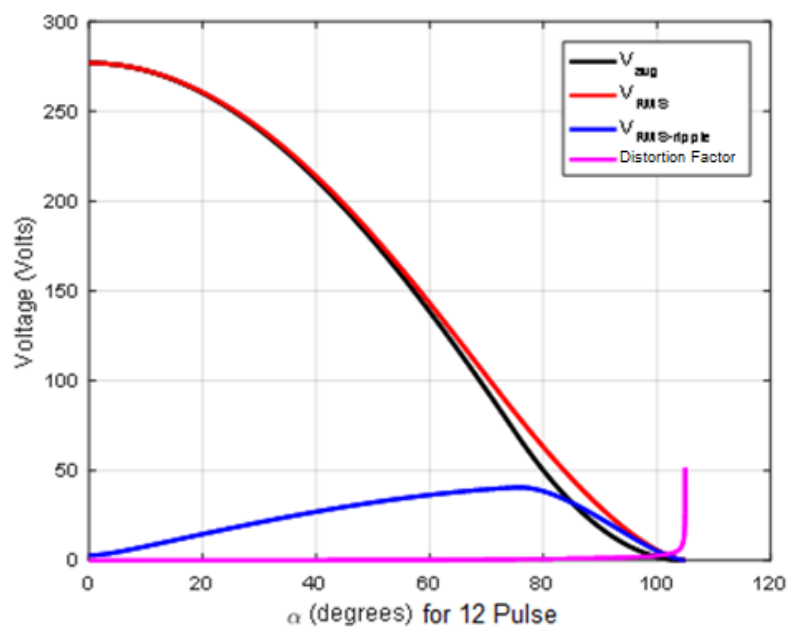

Figure 5. Average Voltage, RMS Voltage, RMS Ripple Voltage, and Distortion Factor 12-pulse TRU

\section{Discussions}

From Figure 4 and 5, it is obtained that the increasing the firing angle $(\alpha)$ in the 6-pulse TRU and 12-pulse TRU on the $115 \mathrm{VAC} / 400 \mathrm{~Hz}$ conversion causes the RMS voltage value and the average voltage to decrease until the firing angle $(\alpha)$ is $120^{\circ}$ for the 6-pulse TRU and the firing angle $(\alpha) 105^{\circ}$ for 12-pulse TRU. Increasing the firing angle $(\alpha)$ in the 6-pulse TRU causes the ripple voltage to rise up to the firing angle $(\alpha) \leq 60^{\circ}$, after the firing angle $(\alpha) \geq 60^{\circ}$, the RMS ripple voltage (VRMS_ripple) decreases. The distortion factor (VRMS_ripple / Vavg) at the firing angle $(\alpha) \leq 60^{\circ}$ has a relatively smaller increase compared than the firing angle $\alpha \geq 60^{\circ}$. Also, the increasing the firing angle $(\alpha)$ of the 12-pulse TRU causes the ripple voltage to rise up to the firing angle $(\alpha) \leq 75^{\circ}$, after the firing angle $(\alpha) \geq 75^{\circ}$, the RMS ripple voltage (VRMS_ripple) decreases.

The distortion factor (VRMS_ripple / Vavg) at the firing angle $(\alpha) \leq 75^{\circ}$ has a relatively smaller increase compared than the firing angle $\alpha \geq 75^{\circ}$. In compliance with MIL STD-704F, Figure 4 for TRU 6-pulses and Figure 5 for 12-pulse TRU, it is obtained that. At the critical angle limit $\alpha=4^{\circ}$, TRU 6-pulse produces a RMS voltage (VRMS) 267V lower than the 12-pulse TRU that produces RMS voltage (VRMS) 276V, while at the critical angle limit $\alpha=4^{\circ}$, the TRU 6-pulse produces an average voltage (Vavg) of 267V lower than the TRU 12-pulse which produces an average voltage (Vavg) of 276V. Furthermore, in compliance with MIL STD-704F, Figure 6 and Table 3 show that at the critical angle limit $\alpha=4^{\circ}$, TRU 6-pulses produces a RMS ripple voltage (VRMS_ripple) 12.65VDC higher than a 12-pulse TRU that produces ripple voltage RMS (VRMS_ripple) 4.13VDC.

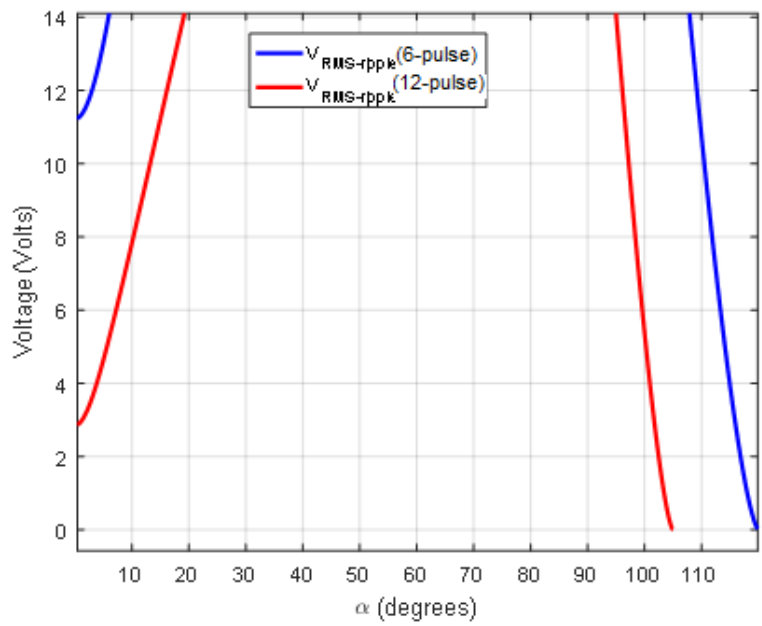

Figure 6. Ripple Voltage for 6-pulses and 12-pulse TRU for compliance with MIL-STD-704F 
In compliance with MIL STD-704F, Figure 7 and Table 3 show that at the critical angle limit $\alpha=$ $4^{\circ}$, the distortion factor (VRMS_ripple / Vavg) of TRU 6-pulse is 0.047 higher than the 12-pulse TRU which results in a distortion factor value (VRMS_ripple / Vavg) 0.015 .

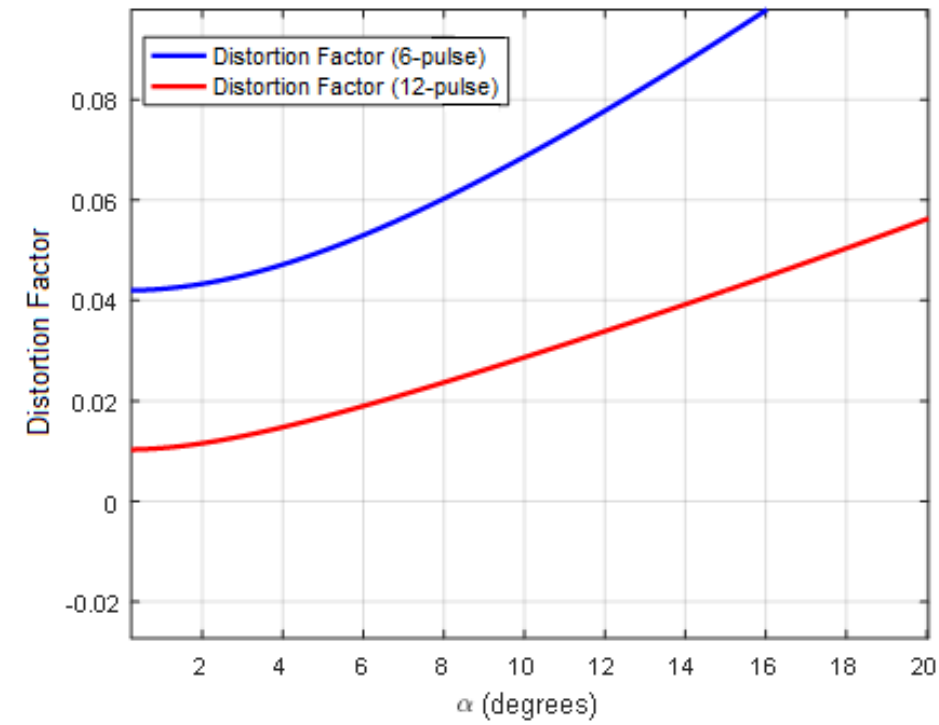

Figure 7. Distortion Factor of 6-pulse and 12-pulse TRU for MIL-STD-704F Compliance

The results of TRU 6-pulses and TRU 12-pulses show that TRU 6-pulses do not meet MIL-STD-704F for output voltage values, ripple voltage limits and distortion factors. Whereas, the 12-pulse TRU meets MIL-STD-704F for output voltage values, ripple voltage limits and distortion factors at $0^{\circ} \leq \alpha \leq 4^{\circ}$.

Table 3. Compliance with MIL-STD-704F

\begin{tabular}{|c|c|c|c|c|c|c|}
\hline Number of & Firing Angle $(\alpha)$ & VRMS & Vavg & VRMS_ripple & Distortion & Compliance \\
\hline \multirow[t]{10}{*}{5 Pulse } & $20^{\circ}$ & 267.6157 & 267.3801 & 11.22 & 0.042 & Not comply \\
\hline & $2.5^{\circ}$ & 267.3885 & 267.1296 & 11.76 & 0.044 & Not comply \\
\hline & $4.0970^{\circ}$ & 266.9966 & 266.6970 & 12.65 & 0.047 & Not comply \\
\hline & $5^{\circ}$ & 266.6800 & 266.3475 & 13.31 & 0.049 & Not comply \\
\hline & $7.5^{\circ}$ & 265.5334 & 265.0814 & 15.56 & 0.058 & Not comply \\
\hline & $10^{\circ}$ & 253.0489 & 251.2553 & 30.07 & 0.119 & Not comply \\
\hline & $12.5^{\circ}$ & 244.9599 & 242.2547 & 36.31 & 0.149 & Not comply \\
\hline & $15^{\circ}$ & 235.3913 & 231.5581 & 42.31 & 0.183 & Not comply \\
\hline & 117.5 & 1.3592 & 0.2357 & 1.23 & 5.679 & Not comply \\
\hline & 120 & 0 & 0 & 0 & $\mathrm{NaN}$ & Not comply \\
\hline \multirow[t]{13}{*}{12 Pulse } & $0^{\circ}$ & 276.8271 & 276.8125 & 2.85 & 0.010 & Comply \\
\hline & $2.5^{\circ}$ & 276.5658 & 276.5450 & 3.39 & 0.012 & Comply \\
\hline & $3^{\circ}$ & 276.4546 & 276.4312 & 3.59 & 0.013 & Comply \\
\hline & $3.5^{\circ}$ & 276.3238 & 276.2973 & 3.83 & 0.014 & Comply \\
\hline & $4^{\circ}$ & 276.1609 & 276.1305 & 4.094 & 0.0148 & Comply \\
\hline & $4.0977^{\circ}$ & 276.1358 & 276.1177 & 4.13 & 0.0150 & Comply \\
\hline & $5^{\circ}$ & 275.7980 & 275.7591 & 4.63 & 0.017 & Not comply \\
\hline & $7.5^{\circ}$ & 274.5020 & 274.4324 & 6.18 & 0.022 & Not comply \\
\hline & $10^{\circ}$ & 272.7192 & 272.6071 & 7.82 & 0.029 & Not comply \\
\hline & $12.5^{\circ}$ & 270.3991 & 270.2312 & 9.53 & 0.035 & Not comply \\
\hline & $15^{\circ}$ & 267.6615 & 267.3803 & 11.22 & 0.042 & Not comply \\
\hline & 102.5 & 2.0129 & 0.5013 & 1.95 & 3.889 & Not comply \\
\hline & 105 & 0 & 0 & 0 & $\mathrm{NaN}$ & Not comply \\
\hline
\end{tabular}




\section{Conclusions}

The investigation on variation of the number of pulses (p) and firing angle $(\alpha)$ to the amplitude ripple voltage, output voltage, and distortion factor of Multi-Pulse Transformer Rectifier Unit (TRU) has been performed to comply with the MIL-STD-704F standards. It is concluded that the TRU 6-pulses do not meet MIL-STD-704F for output voltage values, ripple voltage limits and distortion factors. Whereas, the 12-pulse TRU meets MIL-STD-704F for output voltage values, ripple voltage limits and distortion factors at $0^{\circ} \leq \alpha \leq 4^{\circ}$. It is suggested that all military aircraft may designed using 270VDC for electric power system.

\section{References}

1. Ion Moir and Allan Seabridge, "Third Edition Aircraft System Mechanical, electrical, and avionics subsystem integration", John Wiley \& Sons, Ltd, 2008

2. Setlak L., Ruda E., Review, Analysis and Simulation of Advanced Technology Solutions in Power Electronics Systems (PES) of More Electric Aircraft, World Academy of Science, Engineering and Technology, vol. 9 (10), 2015

3. Venkatesh P1, Dr. M. N. Dinesh2, "Harmonic Analysis of 6-Pulse and 12-Pulse Converter Models".,IJMER ISSN: 2249-6645 .Vol. 4 Iss.9, Sept. 2014.

4. Vitoi, L. A.; Pomilio, J. A.; Brandao, D. I. “Analysis of 12-pulse diode rectifier operating in aircraft systems with constant frequency". In: 14th Brazilian Power Electronics Conference, COBEP 2017. [S.l.: s.n.], 2017. Citado na página 26.

5. Ion Moir and Allan Seabridge, "Military Avionics System", John Wiley \& Sons ISBN: 0-470-01632-9, Ltd, 2008

6. MIL-STD-704F, “Interface standard - Aircraft electric power characteristics”, Department of Defense USA, Mar. 2004. [Online]. Available: http : //www.everyspec.com.

7. Kurt A. Young, "Comparative Analyses Of Multi-Pulse Phase Controlled Rectifiers In Continuous Conduction Mode With A Two-Pole Lc Output Filter For Surface Ship Dc Applications", Naval Postgraduate School, 2013

(C) 2019 by the authors. Submitted for possible open access publication under the terms and conditions of the Creative Commons Attribution (CC BY) license (http://creativecommons.org/licenses/by/4.0/). 